\title{
Selective Heterogeneous Catalytic Hydrogenation of Nitriles to Primary Amines
}

\author{
Krisztina Lévay¹, László Hegedűs ${ }^{1 *}$ \\ 1 Department of Organic Chemistry and Technology, Faculty of Chemical Technology and Biotechnology, Budapest University of \\ Technology and Economics, H-1521 Budapest, P.O.B. 91, Hungary \\ *Corresponding author, e-mail: Ihegedus@mail.bme.hu
}

Received: 02 July 2018, Accepted: 30 August 2018, Published online: 01 October 2018

\begin{abstract}
Primary amines are important intermediates, especially in the area of pharmaceutical, plastic and agrochemical industry. The heterogeneous catalytic hydrogenation of nitriles is one of the most frequently applied process for the synthesis of diverse amines. However, the control of the selectivity is a critical issue in this reaction. Over the past decade, many studies have been reported using heterogeneous transition metal catalysts for the selective reduction of nitriles to the corresponding primary amines. The type of the catalysts, especially, the chemical nature of metals in the catalysts is one of the most important factors to influence the selectivity, the reaction rate, and possibly also the reaction pathway and the deactivation of the catalyst. Thus, this review focuses on the heterogeneous transition metal catalysts and summarizes the recent developments achieved in the selective catalytic hydrogenation of nitriles to primary amines.
\end{abstract}

Keywords

heterogenous catalysis, hydrogenation, nitriles, primary amines, selective reduction

\section{Introduction}

Primary amines are one of the most important intermediates, especially in the area of pharmaceutical, plastic and agrochemical industry. There are several methodologies for the synthesis of primary amines, including the reduction of nitro compounds, amides and the reductive amination of oxo compounds $[1,2]$.

The heterogeneous catalytic hydrogenation of nitriles is the most preferred synthetic method in the industrial production of primary amines. Although the conversion of the nitrile group to a primary amine one takes place relatively easily, but the selectivity of the reaction can be strongly decreased due to the formation of by-products [3-5]. The reaction mechanism of hydrogenation of nitriles was proposed for the first time by von Braun et al. [6] and later modified by Greenfield [7]. Due to the high reactivity of the imine intermediate 2 , the hydrogenation of nitriles 1 leads to a set of consecutive and parallel reactions and results in a mixture of primary $\mathbf{3}$, secondary $\mathbf{4}$ and tertiary amines $\mathbf{5}$, as shown in Fig. 1 . The separation of the reaction products is usually complicated due to the small differences in their boiling points. For this reason, one of the most critical issues is the control of the selectivity. Depending on the structure of the substrate, the nature and amount of the catalyst and the reaction conditions, one of the amine types mentioned above can predominate in the hydrogenation products.

Among these factors, the chemical nature of the catalytic metal has a decisive influence on the composition of the products $[8,9]$. Nevertheless, there are some possibilities to enhance the selectivity to primary amine. With addition of ammonia [7, 10-15] or an appropriate base [7, 16-18] the formation of by-products could be suppressed. Using ammonia, however, high primary amine selectivities were only reported with Raney ${ }^{\circledR}$ nickel [1014] or rhodium [15] catalysts, while over supported palladium or platinum catalysts, the main product remained the secondary / tertiary amine even in the presence of five equivalents of $\mathrm{NH}_{3}[7,13]$. Furthermore, the positive effect of the bases (e.g. aqueous solutions of $\mathrm{NaOH}, \mathrm{LiOH}, \mathrm{KOH}$ or $\mathrm{Na}_{2} \mathrm{CO}_{3}$ ) on the product distribution was also revealed for only cobalt and nickel catalysts [7, 16-18].

Avoiding the reaction between the primary amine (3) and the imine intermediate (2) also represents a possibility to effectively minimize the formation of secondary (4) 


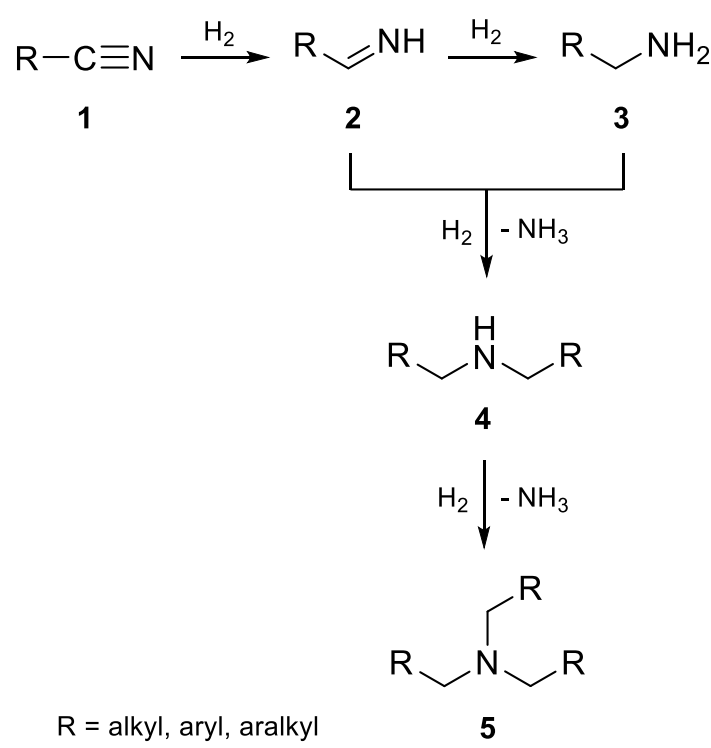

Fig. 1 Reaction pathways in the hydrogenation of nitriles

and/or tertiary amines (5). This can be obtained by forming a salt with acids [19-21] or by acylating the amino group with acetic anhydride [22-24].

Taking into account all of these considerations, this review summarizes the recent developments achieved in the selective heterogeneous catalytic hydrogenation of nitriles to primary amines. The information gathered is discussed on the basis of the chemical nature of the catalytic metals used in this hydrogenation.

\section{Base metal catalysts}

\subsection{Nickel-catalyzed hydrogenations}

Nickel is a typically applied catalyst in the hydrogenation of nitriles in different forms, such as Raney-type one [10-14, 16-18, 24, 25], supported on silica [7, 26-30], alumina [31-34] or sepiolite [35], as well as NiAl alloy [36], Ni nanoparticles [37-39] or $\mathrm{Ni}_{2} \mathrm{P}$ [40].

In 2009, Hoffer and Moulijn [25] investigated the hydrogenation of aliphatic dinitriles (succinonitrile $\mathbf{6 a}$, glutaronitrile $\mathbf{6 b}$ and adiponitrile $\mathbf{6 c}$ ) to the corresponding aminonitriles (7a-c) at $77{ }^{\circ} \mathrm{C}$ and 50 bar over commercial Raney ${ }^{\circledR}-\mathrm{Ni}$ catalyst (Fig. 2). Based on their results, the reactivity of the substrates and the mechanism of the hydrogenation were highly influenced by the hydrocarbon chain length. Short dinitriles, like compound $\mathbf{6 a}$, exhibit stronger adsorption on the catalyst surface than longer dinitriles, such as compound 6c. Furthermore, with increasing of the hydrocarbon chain length, a substantial decrease was achieved in the yields of the partial hydrogenated intermediates $(7 \mathbf{a}-\mathbf{c})$, due to the enhanced competitiveness of dinitriles (6a-c) and aminonitriles (7a-c) for the same active sites. Moreover, a longer chain length had a negative effect on the reactivity of the first $\mathrm{C} \equiv \mathrm{N}$ bond, because the destabilizing effect of the electron-withdrawing second $\mathrm{C} \equiv \mathrm{N}$ bond was weakened. Thus, it was found that both the reaction rate and the adsorption strength decrease in the following order: succinonitrile (6a) $>$ glutaronitrile $(\mathbf{6 b})>$ adiponitrile (6c) (Table 1).

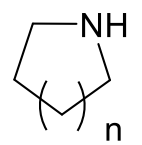

10a-c

$\mathrm{H}_{2} \uparrow-\mathrm{NH}_{3}$

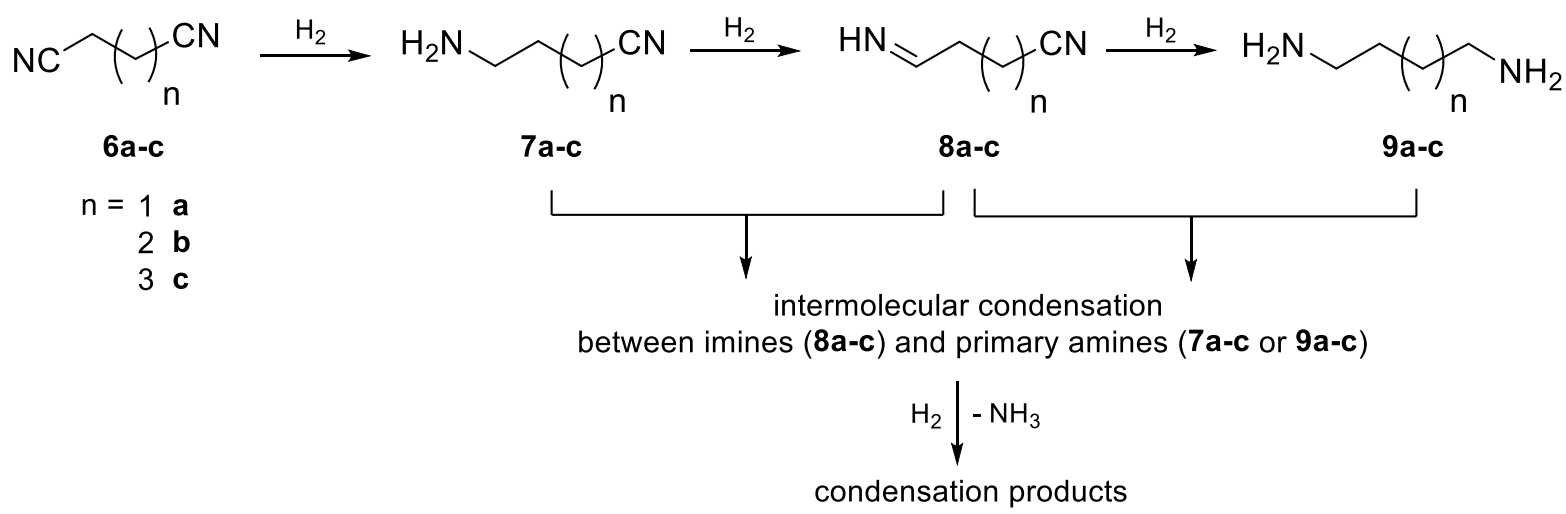

Fig. 2 Mechanism of the catalytic hydrogenation of dinitriles, such as succinonitrile (6a), glutaronitrile (6b) and adiponitrile (6c) 
Table 1 Hydrogenation of dinitriles over Raney ${ }^{\circledR}$-Ni catalyst

\begin{tabular}{lccc}
\hline Entry & Substrate & $\begin{array}{c}\text { Activity } \\
\left(\mathrm{mol} \mathrm{kg}_{\text {cat }}{ }^{-1} \mathrm{~min}^{-1}\right)\end{array}$ & $\begin{array}{c}\text { Selectivity to the } \\
\text { corresponding } \\
\text { aminonitrile (7a-c) }\end{array}$ \\
\hline 1 & $\mathbf{6 a}$ & 0.78 & 95 \\
2 & $\mathbf{6 b}$ & 0.44 & 90 \\
3 & $\mathbf{6 c}$ & 0.28 & 70 \\
\hline Conditions: $77^{\circ} \mathrm{C}, 50$ bar ethylenediamine (solvent)
\end{tabular}

Conditions: $77^{\circ} \mathrm{C}, 50$ bar, ethylenediamine (solvent)

In 2012, Apesteguía et al. [27] studied the liquid-phase hydrogenation of butyronitrile to butylamine over silica supported transition metal ( $\mathrm{Ni}, \mathrm{Co}, \mathrm{Ru}, \mathrm{Cu}, \mathrm{Pd}, \mathrm{Pt}$ ) catalysts at $100{ }^{\circ} \mathrm{C}$ and 13 bar, in ethanol. The butylamine selectivity was in the following order: $\mathrm{Ni}>\mathrm{Co}>\mathrm{Ru}>\mathrm{Pt}$. However, the formation of the desired product was not observed over $\mathrm{Cu} / \mathrm{SiO}_{2}$ and $\mathrm{Pd} / \mathrm{SiO}_{2}$ catalysts due to the fast deactivation. Furthermore, $\mathrm{Pt} / \mathrm{SiO}_{2}$ produced mainly dibutylamine and only minor amounts of butylamine and tributylamine. In an attempt to reduce the formation of by-products, $\mathrm{Ni} / \mathrm{SiO}_{2}, \mathrm{Co} / \mathrm{SiO}_{2}, \mathrm{Ru} / \mathrm{SiO}_{2}$ (the latter two will be discussed in Sections 2.2 and 3.2) catalysts were tested to optimize the reaction conditions (solvents, temperature, pressure). The highest selectivity to butylamine (84\%) was achieved in ethanol (Table 2, entry 1), while using benzene, toluene or cyclohexane the primary amine selectivity significantly decreased to $63-39 \%$ (Table 2, entries 2-4) [28]. These results suggest that using a protic solvent influences the strength of the solvent-butylamine interaction in the liquid phase, which positively affects the selectivity of primary amine over $\mathrm{Ni} / \mathrm{SiO}_{2}$. Ethanol, as a H-bond donor solvent, strongly interacts with the $\mathrm{H}$-bond acceptor butylamine and solvates in the liquid phase. The butylamine molecules are then surrounded by

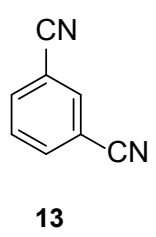

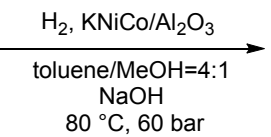

$80^{\circ} \mathrm{C}, 60$ ba
Fig. 3 Hydrogenation of isophthalonitrile (11) to $m$-xylylenediamine (12) over a $K$-doped $\mathrm{NiCo} / \mathrm{Al}_{2} \mathrm{O}_{3}$ catalyst

alcohol ones that inhibit butylamine adsorption on the catalyst and thereby, decrease the formation of by-products.

In 2016, Han et al. [29] also investigated the hydrogenation of adiponitrile (6c) to 6-aminocapronitrile (7c) and 1,6-hexamethylenediamine (9c), which are very important monomers in some industrial processes for manufacturing synthetic fibers (nylon-6 and nylon-6,6), but his time over a $\mathrm{Ni} / \mathrm{SiO}_{2}$ catalyst prepared by direct reduction of $\mathrm{Ni}\left(\mathrm{NO}_{3}\right)_{2} /$ $\mathrm{SiO}_{2}$. According to the previously described mechanism (Fig. 2), this catalyst system effectively inhibited the condensation reactions by promoting the hydrogenation of adsorbed imine (8c). Good selectivity to primary amines (79\% for $7 \mathbf{c}$ and 9c) was achieved, after $86 \%$ conversion of $6 \mathbf{c}$, in methanol, in the presence of $\mathrm{NaOH}$, at $80^{\circ} \mathrm{C}$ and 30 bar.

In 2014, Liu and Wang [31] reported the selective hydrogenation of isophthalonitrile (11) to $m$-xylylenediamine (12) over Ni-Co on alumina catalysts modified by potassium (Fig. 3). The reactions were carried out at $80^{\circ} \mathrm{C}$ and 60 bar, in the presence of basic additives. It was observed that the K-modification considerably decreased the catalyst acidity. Besides, when $\mathrm{KNiCo} / \mathrm{Al}_{2} \mathrm{O}_{3}(\mathrm{~K}: 3 \mathrm{wt} \%)$ was applied, the catalyst acidity was reduced by $82 \%$, and the selectivity to 12 increased from $45.5 \%$ to $99.9 \%$ in comparison to the unmodified catalyst.

Table 2 Effect of solvents in the hydrogenation of butyronitrile

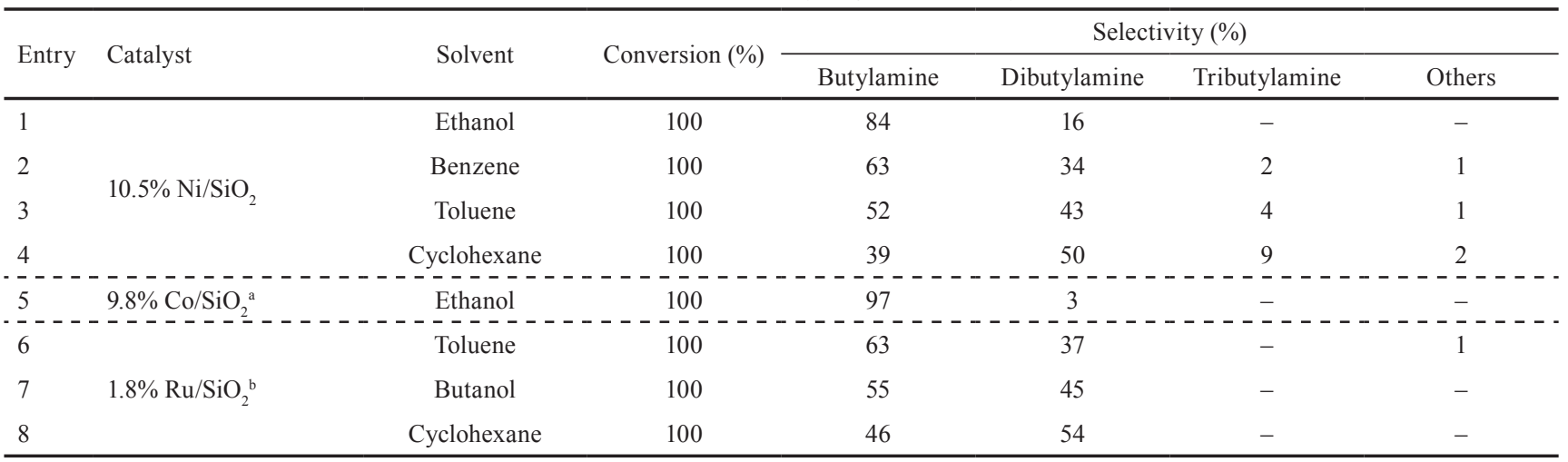

Conditions: $3 \mathrm{~cm}^{3}$ butyronitrile, $1.0 \mathrm{~g}$ catalyst, $150 \mathrm{~cm}^{3}$ solvent, $100{ }^{\circ} \mathrm{C}, 13$ bar

${ }^{\mathrm{a}} 70{ }^{\circ} \mathrm{C}, 25$ bar

${ }^{\mathrm{b}} 130{ }^{\circ} \mathrm{C}$ 


\subsection{Hydrogenations over cobalt}

Cobalt is also a frequently used catalytic metal in the hydrogenation of nitriles in Raney-type [12, 14, 17, 24] or supported [7, 27, 30, 31, 41-43] forms.

In 2004, Ansmann and Benisch [41] developed an industrially feasible process for preparing primary amines by cobalt-catalyzed hydrogenation of both aliphatic and aromatic nitriles. Thus, homoveratrylamine, an important pharmaceutical intermediate in the synthesis of papaverine (antispasmodic drug), could selectively be obtained by the reduction of 3,4-dimethoxybenzyl cyanide over $70 \%$ $\mathrm{Co} / \mathrm{SiO}_{2}$, in the presence of $\mathrm{NH}_{3}$, at $80{ }^{\circ} \mathrm{C}$ and 80 bar.

In 2012, Apesteguía et al. [27] also investigated the liquid-phase hydrogenation of butyronitrile to butylamine over a $9.8 \% \mathrm{Co} / \mathrm{SiO}_{2}$ catalyst, in ethanol, at $70{ }^{\circ} \mathrm{C}$ and 25 bar (Table 2, entry 5). Among the catalytic metals tested, this one provided the best selectivity to butylamine (97\%).

In 2017, Shen et al. [42] developed an efficient metal-organic framework (MOF)-derived $\mathrm{N}$-doped $\mathrm{Co} / \mathrm{C}$ catalyst system for the transfer hydrogenation of nitriles to primary amines under base-free conditions. The first step in the preparation of the catalyst was the synthesis of Co-MOF, where a mixture of $\mathrm{Co}(\mathrm{NO})_{3} \cdot 6 \mathrm{H}_{2} \mathrm{O}$, terephthalic acid (13), triethylenediamine (14) and $N, N$-dimethylformamide were added to the autoclave and heated at $120^{\circ} \mathrm{C}$ for $2 \mathrm{~d}$. These stages were followed by the direct pyrolysis of the $N$-containing Co-MOF under inert atmosphere and at $900{ }^{\circ} \mathrm{C}$, where the $N$-containing ligands were transformed into graphitic $N$-doped carbon to provide Lewis basic sites for the catalysts, while the $\mathrm{Co}^{2+}$ ions were reduced to Co nanoparticles (NPs) which were dispersed on $N$-doped carbon (Fig. 4). The hydrogenation of different nitriles to primary amines were accomplished with high selectivity (>90\%) using this catalyst system, in the presence of isopropyl alcohol as proton-donor and solvent (Table 3 ). The catalytic reactions were carried out in $\mathrm{N}_{2}$ atmosphere at $80{ }^{\circ} \mathrm{C}$. Furthermore, the catalysts exhibited good recyclability even after four runs, and no loss of conversion and selectivity was observed.

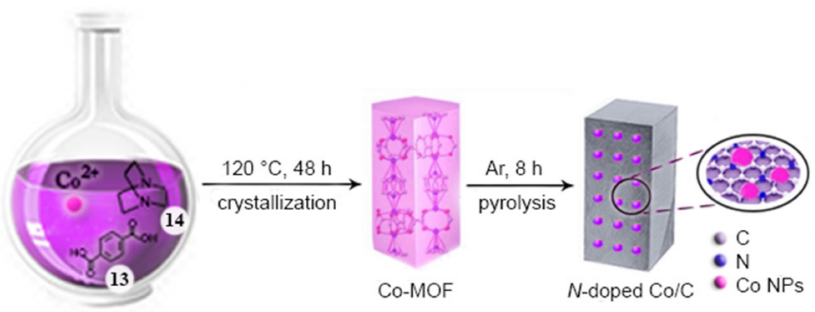

Fig. 4 Schematic illustration of the process used for the preparation of the $N$-doped $\mathrm{Co} / \mathrm{C}$ catalyst
Table 3 Hydrogenation of aromatic nitriles over $N$-doped Co/C catalyst

\begin{tabular}{lccc}
\hline & & & \\
\cline { 3 - 4 }
\end{tabular}

Conditions: $0.5 \mathrm{mmol}$ nitrile, $1 \mathrm{~cm}^{3} i$-PrOH, $80^{\circ} \mathrm{C}$ ${ }^{\mathrm{a}} 100{ }^{\circ} \mathrm{C}$

In the same year, the Beller's group [43] prepared a heterogenous nanostructured cobalt catalyst by the pyrolysis of a cobalt complex $\left[\mathrm{Co}(\mathrm{OAc})_{2} \cdot 4 \mathrm{H}_{2} \mathrm{O}\right]$ containing nitrogen-based ligand (1,10-phenanthroline) on $\alpha-\mathrm{Al}_{2} \mathrm{O}_{3}$ support. The determination of the optimal pyrolysis temperature $\left(800{ }^{\circ} \mathrm{C}\right)$ played a crucial role in the catalytic performance. With this catalyst system synthesized, heptanenitrile was selectively hydrogenated to 1-heptylamine

Table 4 Hydrogenation of (hetero)aromatic nitriles over $\mathrm{Co} / \alpha-\mathrm{Al}_{2} \mathrm{O}_{3}$

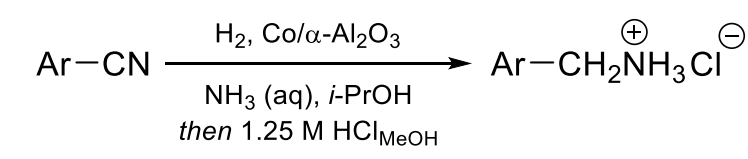

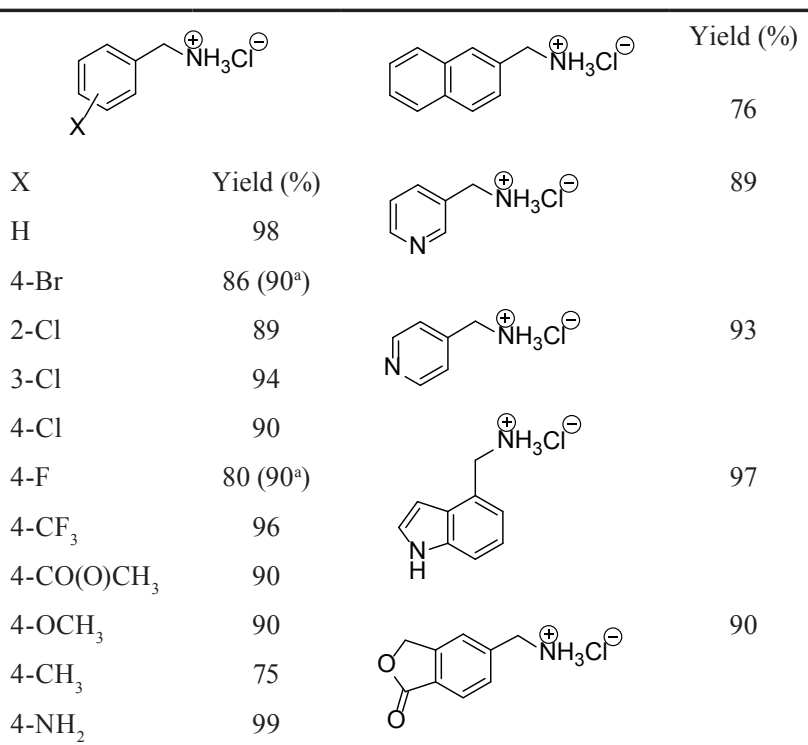

Conditions: $0.5 \mathrm{mmol}$ nitrile, $2 \mathrm{~cm}^{3} i$-PrOH, $130{ }^{\circ} \mathrm{C}, 40$ bar, $2 \mathrm{~h}$ ${ }^{\mathrm{a}} 85^{\circ} \mathrm{C}, 5 \mathrm{bar}$ 
with complete conversion ( $24 \mathrm{~h}$ ), in $98 \%$ yield, and only $2 \%$ of by-products were detected. The hydrogenation was performed at 5 bar and $85{ }^{\circ} \mathrm{C}$ in isopropyl alcohol and in the presence of an optional amount of ammonia. The recyclability of the catalyst was investigated, and no apparent loss was observed in the conversion and selectivity, even up to eight runs. By extending the hydrogenation process, under standard conditions, several aromatic nitriles were converted to the desired primary amines ( $\mathrm{HCl}$ salts) with good to excellent yields (75-99\%, Table 4). In general, the catalyst allowed wide functional group tolerance.

\subsection{Cu-mediated reductions}

Copper is a seldom used catalytic metal during the reduction of nitriles, and it is typically applied in supported form [30, 44, 45].

In 2013, Burri et al [44] reported the gas-phase hydrogenation of benzonitrile to benzylamine over magnesia supported copper catalysts. High primary amine selectivity (near $100 \%$ ) was achieved over $12 \% \mathrm{Cu} / \mathrm{MgO}$, in the absence of any additives, at $240{ }^{\circ} \mathrm{C}$ and $1 \mathrm{bar}$, but no complete conversion of benzonitrile was observed (50-60\%). However, using the inexpensive copper could be an efficient alternative for this hydrogenation.

In 2015, Apesteguía and his co-workers [30] investigated the copper-catalyzed hydrogenation of cinnamonitrile (15) to cinnamylamine (16), in liquid phase (Fig. 5). Over a highly-dispersed $11 \% \mathrm{Cu} / \mathrm{SiO}_{2}$ catalyst $74 \%$ selectivity to $\mathbf{1 6}$ was achieved in toluene, after a complete conversion of 15 , at $100{ }^{\circ} \mathrm{C}$ and $40 \mathrm{bar}$. It was found that the relatively high primary amine selectivity was due to a special catalyst preparation (chemisorption-hydrolysis) method.

\section{Precious metal catalysts}

\subsection{Hydrogenations over palladium}

Among the precious metals, palladium is the most frequently used heterogeneous catalyst in the hydrogenation of nitriles, exclusively in supported form: on activated carbon [46-53], on alumina [51, 52, 54-62], on MCM-41 [63] or on silica [64].

In 2005, our research group [46] developed a process for the selective liquid-phase heterogeneous catalytic hydrogenation of nitriles to primary amines. Benzonitrile was hydrogenated to benzylamine under mild reaction conditions $\left(30{ }^{\circ} \mathrm{C}, 6 \mathrm{bar}\right)$, over $10 \% \mathrm{Pd} / \mathrm{C}$ (Selcat Q) catalyst, in a mixture of two immiscible solvents (e.g. water/dichloromethane) and in the presence of a medium acidic additive $\left(\mathrm{NaH}_{2} \mathrm{PO}_{4}\right)$. Full conversion,

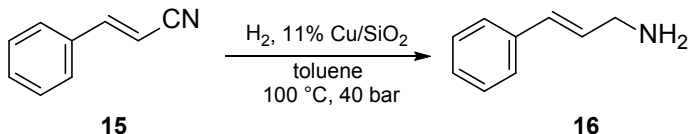

Fig. 5 Hydrogenation of cinnamonitrile (15) to cinnamylamine (16) over $11 \% \mathrm{Cu} / \mathrm{SiO}_{2}$

excellent selectivity (95\%) and isolated yield (85-90\%) could be achieved by applying this method. In addition, the purity of the product was over $99 \%$ without using any special purification procedures.

Later, in 2008, this method was extended to the selective catalytic hydrogenation of benzyl cyanide to 2-phenylethylamine [47]. Although the conversion of benzyl cyanide was complete, lower isolated yield $(40 \%)$ and selectivity $(45 \%)$ to primary amine were achieved than in the reduction of benzonitrile reported previously [45]. Based on the molecular modelling calculations, there are no significant differences in the energy profiles of the side-reactions. The reactants have very similar reactivity, therefore, other effects must be responsible for the primary amine selectivity. The adsorption modes of these imine types on $\operatorname{Pd}(111)$ revealed that benzaldimine can adsorb on palladium stronger than 2-phenylethylimine. Therefore, and also due to the different structures of their minimal energy conformers, the chance of by-product formation increased in case of 2-phenylethylimine.

In 2014, Beller et al. [49] reported the catalytic transfer hydrogenation of aromatic nitriles to the corresponding primary amines over a $10 \%$ palladium on carbon catalyst and applying ammonium formate as a hydrogen donor. Aromatic nitriles containing electron-donating, as well as electron-withdrawing groups were compatible with the catalytic system and good to excellent yields of the desired primary amines (51-98\%) were obtained under mild reaction conditions $\left(25-40{ }^{\circ} \mathrm{C}\right)$, as shown in Table 5 .

In 2013, Arai and his co-workers [55] investigated the hydrogenation of benzonitrile to benzylamine over a $\mathrm{Pd} /$ $\mathrm{Al}_{2} \mathrm{O}_{3}$ catalyst in a multiphase reaction media including both pressurized $\mathrm{CO}_{2}$ and $\mathrm{H}_{2} \mathrm{O}$. The catalytic transformation was realized at $50{ }^{\circ} \mathrm{C}, 20$ bar $\mathrm{H}_{2}$ and 50 bar $\mathrm{CO}_{2}$ and enabled full substrate conversion after $24 \mathrm{~h}$ and high selectivity to benzylamine (98\%) (Table 6, entry 1). Furthermore, no catalyst deactivation occurred in this medium. The enhanced selectivity to the primary amine may result from a synergistic effect of $\mathrm{CO}_{2}$ and $\mathrm{H}_{2} \mathrm{O}$. In the organic phase (benzonitrile) produced benzylamine molecules likely react with $\mathrm{CO}_{2}$ giving a carbamate salt and 
Table 5 Transfer hydrogenation of (hetero)aromatic nitriles

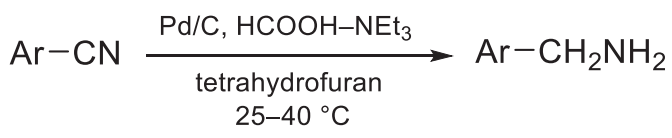

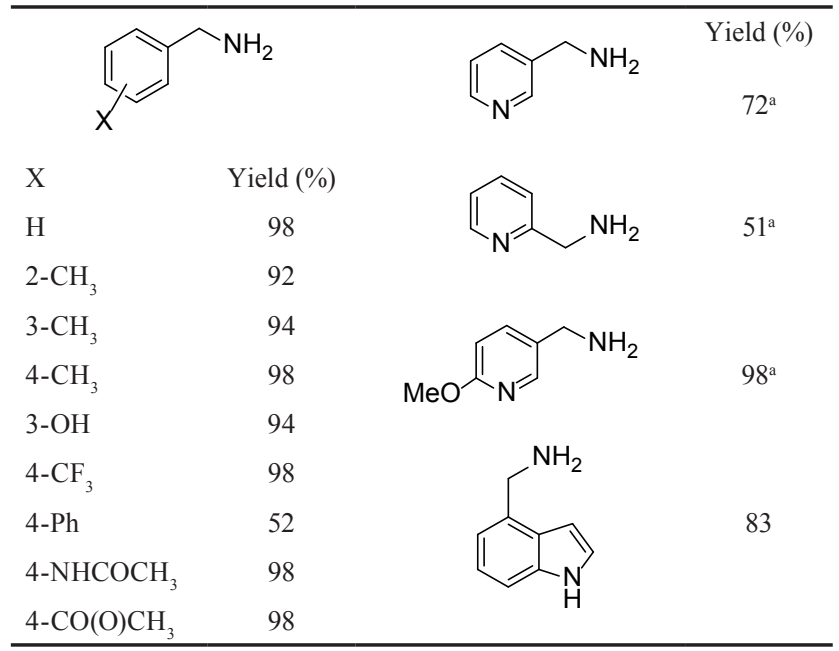

Conditions: $0.38 \mathrm{mmol}$ nitrile, $1 \mathrm{~cm}^{3}$ tetrahydrofuran, $1 \mathrm{~cm}^{3} \mathrm{HCOOH}-$ $\mathrm{NEt}_{3}(18.5: 1), 25^{\circ} \mathrm{C}, 1-12 \mathrm{~h}$, ${ }^{\mathrm{a}} 40{ }^{\circ} \mathrm{C}$

this water-soluble species moves into the aqueous phase, reducing the chance for side-reactions.

Later, in 2015, the same group [56] also studied the hydrogenation of benzyl cyanide over a $\mathrm{Pd} / \mathrm{Al}_{2} \mathrm{O}_{3}$ catalyst, but this time in the presence of hexane, water and $\mathrm{CO}_{2}$. This reduction was carried out at $50{ }^{\circ} \mathrm{C}, 20$ bar $\mathrm{H}_{2}$ and 50 bar $\mathrm{CO}_{2}$. In this case, a partial substrate conversion (56\%) and high selectivity (90\% to 2-phenylethylamine) were obtained (Table 6, entry 2). However, the full conversion of benzyl cyanide was accompanied with lower selectivity to 2-phenylethylamine.

In 2016 Arai et al. [57] also investigated the effectiveness of the multiphase medium including toluene or hexane, water, and $\mathrm{CO}_{2}$ for the selective hydrogenation of different nitriles, such as propionitrile, hexanenitrile and 4-phenylbenzonitrile over a $\mathrm{Pd} / \mathrm{Al}_{2} \mathrm{O}_{3}$ catalyst. The process was effective for the selective hydrogenation of propio-nitrile (Table 6, entry 3 ) and hexanenitrile (Table 6, entry 4), similar to benzonitrile and benzyl cyanide, but not for 4-phenylbenzonitrile. In the latter case, neither the desired products nor the secondary amine were detected in the toluene- $\mathrm{CO}_{2}-$ $\mathrm{H}_{2} \mathrm{O}$ mixture (Table 6, entry 5). Although 32\% conversion was observed, the products were unable to be identified. However, very good selectivity ( $>99$ ) was achieved, when the hydrogenation of 4-phenylbenzonitrile was carried out in toluene and $\mathrm{CO}_{2}$ medium without water (Table 6, entry 6).

In 2018, Yoshimura et al. [61] studied the hydrogenation of valeronitrile (17) to pentylamine (18a) over $10 \%$ $\mathrm{Pd} / \mathrm{C}, 5 \% \mathrm{Pd} / \mathrm{Al}_{2} \mathrm{O}_{3}$, and $25 \% \mathrm{Pd}-5 \% \mathrm{Au} / \mathrm{Al}_{2} \mathrm{O}_{3}$ catalysts (Table 7). The experiments were carried out in acetic acid, at $50{ }^{\circ} \mathrm{C}$ and 1.5 bar. According to their results, $\mathrm{Pd} / \mathrm{Al}_{2} \mathrm{O}_{3}$ produced a better selectivity to $\mathbf{1 8 a}(81 \%$, Table 7 , entry 2$)$ compared to $\mathrm{Pd} / \mathrm{C}$ ( $56 \%$, Table 7 , entry 1$)$, probably due to differences in the number of acidic sites on the surface of activated carbon and alumina.

Even better primary amine selectivity (89\%, Table 7 , entry 3) was achieved when the reduction was catalyzed by active Pd-monomers released from alloyed Au-clusters in $\mathrm{Pd}-\mathrm{Au} / \mathrm{Al}_{2} \mathrm{O}_{3}$. The selectivity to $\mathbf{1 8 a}$ was enhanced to above $99 \%$ by decreasing the temperature from 50 to $25^{\circ} \mathrm{C}$ and increasing the pressure from 1.5 to 8 bar (Table 7, entry 4).

\subsection{Ruthenium-catalyzed reductions}

Ruthenium can also be used for the heterogeneous catalytic hydrogenation of nitriles in supported form [65-67] or as nanoparticles [68].

Ionic liquid-based, multiphase reaction system was investigated in the hydrogenation of propionitrile over $\mathrm{Ru} / \mathrm{C}$ by Wasserscheid and his co-workers [65]. Two different approaches (I and II) were introduced to improve the

Table 6 Hydrogenation of nitriles in different reaction media

\begin{tabular}{|c|c|c|c|c|c|c|}
\hline \multirow{2}{*}{ Entry } & \multirow{2}{*}{ Substrate } & \multirow{2}{*}{ Medium } & \multirow{2}{*}{ Reaction time (h) } & \multirow{2}{*}{ Conversion (\%) } & \multicolumn{2}{|c|}{ Selectivity (\%) } \\
\hline & & & & & Primary amine & Secondary amine \\
\hline 1 & Benzonitrile $^{a}$ & $\mathrm{CO}_{2}-\mathrm{H}_{2} \mathrm{O}$ & 24 & $>99$ & 98 & 2 \\
\hline 2 & Benzyl cyanide & Hexane $-\mathrm{CO}_{2}-\mathrm{H}_{2} \mathrm{O}$ & 1 & 56 & 90 & 10 \\
\hline 3 & Propionitrile & Toluene- $-\mathrm{CO}_{2}-\mathrm{H}_{2} \mathrm{O}$ & 1 & 32 & 82 & 18 \\
\hline 4 & Hexanenitrile & Hexane $-\mathrm{CO}_{2}-\mathrm{H}_{2} \mathrm{O}$ & 5 & 32 & $>99$ & 0 \\
\hline 5 & 4-Phenylbenzonitrile & Toluene- $-\mathrm{CO}_{2}-\mathrm{H}_{2} \mathrm{O}$ & 1 & 32 & 0 & 0 \\
\hline 6 & 4-Phenylbenzonitrile & Toluene- $-\mathrm{CO}_{2}$ & 1 & 76 & $>99$ & 0 \\
\hline
\end{tabular}

Conditions: $50{ }^{\circ} \mathrm{C}, 20$ bar $\mathrm{H}_{2}, 50$ bar $\mathrm{CO}_{2}$

${ }^{\mathrm{a}} 50{ }^{\circ} \mathrm{C}, 40$ bar $\mathrm{H}_{2}, 10$ bar $\mathrm{CO}_{2}$ 
Table 7 Hydrogenation of valeronitrile (17) over Pd on alumina catalysts

\begin{tabular}{|c|c|c|c|c|c|}
\hline $\begin{array}{c}\mathrm{CH}_{3}\left(\mathrm{CH}_{2}\right)_{3} \mathrm{CN}- \\
17\end{array}$ & $\begin{array}{c}\mathrm{H}_{2} \text {, Pd-catalyst } \\
\text { acetic acid } \\
50^{\circ} \mathrm{C}, 1.5 \text { bar }\end{array}$ & \multicolumn{4}{|c|}{$\mathrm{C}_{5} \mathrm{H}_{11} \mathrm{NH}_{2}+\left(\mathrm{C}_{5} \mathrm{H}_{11}\right)_{2} \mathrm{NH}+\left(\mathrm{C}_{5} \mathrm{H}_{11}\right)_{3} \mathrm{~N}$} \\
\hline \multirow{2}{*}{ Entry } & \multirow{2}{*}{ Catalyst } & & \multicolumn{3}{|c|}{ Selectivitiy (\%) } \\
\hline & & & $18 \mathbf{a}$ & $18 b$ & $18 \mathrm{c}$ \\
\hline 1 & $10 \% \mathrm{Pd} / \mathrm{C}$ & & 56 & 29 & 7 \\
\hline 2 & $5 \% \mathrm{Pd} / \mathrm{Al}_{2} \mathrm{O}_{3}$ & & 81 & 4 & 0 \\
\hline 3 & $25 \% \mathrm{Pd}-5 \% \mathrm{Au} / \mathrm{Al}_{2} \mathrm{O}_{3}$ & & 89 & 7 & 0 \\
\hline $4^{\mathrm{a}}$ & $25 \% \mathrm{Pd}-5 \% \mathrm{Au} / \mathrm{Al}_{2} \mathrm{O}_{3}$ & & $>99$ & 0 & 0 \\
\hline
\end{tabular}

Conditions: $1.7 \mathrm{~g}$ valeronitrile, $50 \mathrm{~cm}^{3}$ acetic acid, $50{ }^{\circ} \mathrm{C}, 1.5 \mathrm{bar}, 5 \mathrm{~h}$ ${ }^{\mathrm{a}} 25^{\circ} \mathrm{C}, 8$ bar

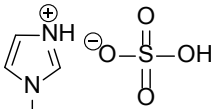

$$
\begin{aligned}
& \left(\mathrm{CH}_{2}\right)_{3} \mathrm{CH}_{3}
\end{aligned}
$$

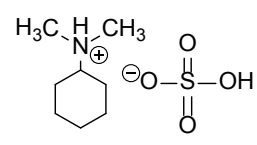

20

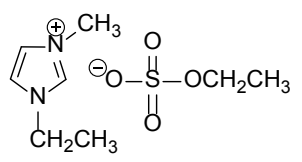

21
Fig. 6 Chemical structures of the ionic liquids applied for the hydrogenation of propionitrile over $\mathrm{Ru} / \mathrm{C}$

selectivity to primary amines. Both methods were carried out at $100{ }^{\circ} \mathrm{C}$ and 100 bar. In method I, the application of Brønsted acidic ionic liquids [1-butylimidazolium hydrogen sulfate (19) or N,N-dimethylcyclohexylammonium hydrogen sulfate (20), Fig. 6] resulted in high selectivity to propylamine ( $85 \%$ ) even in complete nitrile conversion. In the presence of a Brønsted acidic ionic liquid, the formed primary amine was protonated, thus preventing the primary amine reaction with the imine. In this case the $\mathrm{Ru} / \mathrm{C}$ catalyst was dispersed in the ionic liquid phase, and both the hydrogenation and protonation of the product took place in this phase. Thus, the role of the organic phase (1,2,4-trichlorobenzene) was only the dissolution of hydrogen and the propionitrile. However, the direct recycling the $\mathrm{Ru} / \mathrm{C}$-Brønsted acidic ionic liquid phase was not possible after a basic work-up, because it led to the complete deprotonation of the ionic liquid cation to the corresponding amine.

In approach II (Fig. 7), the hydrogenation occurred in an aprotic ionic liquid [1-ethyl-3-methylimidazolium ethyl sulfate (21), Fig. 6] which included the suspended heterogeneous Ru-catalyst. The formed propylamine was not protected from a successive protonation step, but directly extracted into an organic solvent (1,2,4-trichlorobenzene) presenting better solubility for the amine compared to the nitrile. This resulted in the low concentration of primary amine, even when the nitrile conversion was high. Complete conversion and good selectivity (70\%) could be

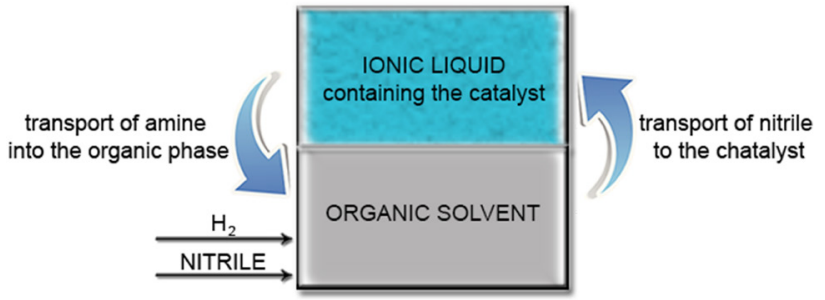

Fig. 7 Approach II: the extraction of primary amine by an organic phase from the aprotic ionic liquid (21) containing the suspended Ru-catalyst

achieved by using this method. Besides, one of its primary advantages is that the extraction from the reaction phase also means the product isolation step. Therefore, the recycling of the ionic liquid catalyst phase can be performed without any additional steps for product separation. Moreover, the recyclability of the ionic liquid / catalyst phase by simple phase separation could be demonstrated.

In 2014, Apesteguía et al. [66] also investigated the effect of various solvents on the activity and selectivity for the liquid-phase hydrogenation of butyronitrile to butylamine (13 bar, $130{ }^{\circ} \mathrm{C}$ ), but this time over a $1.8 \% \mathrm{Ru} / \mathrm{SiO}_{2}$ catalyst (Table 2, entries 6-8). Regarding the product distribution, $\mathrm{Ru} / \mathrm{SiO}_{2}$ formed a mixture of butylamine and dibutylamine. The best selectivity to primary amine (63\%) was achieved, when toluene was used as a solvent (Table 2, entry 6).

In 2015, Muratsugu et al. [67] reported a decarbonylation-promoted $\mathrm{Ru}$ nanoparticles formation from $\mathrm{Ru}_{3}(\mathrm{CO})_{12}$ precursor, wich were dispersed on a basic $K$-doped $\mathrm{Al}_{2} \mathrm{O}_{3}$ support surface. This catalyst was active and selective for the hydrogenation of nitriles to the appropriate primary amines without using any basic additives (e.g. ammonia). For example, in the saturation of valeronitrile (17), the ruthenium species supported on K-Alu C (K: 4 wt\%, Ru: 2 wt $\%$ ) formed pentylamine (18a) with high selectivity (97\%) at 31\% conversion of 17 after $1.5 \mathrm{~h}$, in heptane, at $70{ }^{\circ} \mathrm{C}$ and 1 bar. Due to an increased reaction time $(12 \mathrm{~h})$, the conversion of 17 raised to above $99 \%$, and the selectivity to pentylamine $(96 \%)$ remained a very similar value to the previous one.

\subsection{Rh-mediated hydrogenations}

Rhodium is also a rarely used heterogeneous catalyst in the hydrogenation of nitriles $[15,69]$.

In 2010, Chatterjee and her co-workers [69] studied the semi-hydrogenation of adiponitrile (6c) to 6-aminocapronitrile (7c) over $5 \% \mathrm{Rh} / \mathrm{Al}_{2} \mathrm{O}_{3}$ avoiding the formation of 1,6-hexamethylenediamine (9c) (Fig. 2). The desired product was effectively synthesized with complete 
Table 8 Hydrogenation of aromatic dinitriles over $5 \% \mathrm{Rh} / \mathrm{Al}_{2} \mathrm{O}$

\begin{tabular}{lll}
\hline Entry & Conversion (\%) & Yield (\%) \\
\hline
\end{tabular}

Conditions: $1 \mathrm{~g}$ substrate, $0.1 \mathrm{~g}$ catalyst, 8 bar $\mathrm{CO}_{2}, 4$ bar $\mathrm{H}_{2}, 80^{\circ} \mathrm{C}, 6 \mathrm{~h}$

selectivity to $7 \mathbf{c}$, at $80{ }^{\circ} \mathrm{C}$ in supercritical carbon dioxide $\left(\mathrm{scCO}_{2}\right)$ and without any additive or the use of any organic solvent. The maximum conversion was 97\% after $6 \mathrm{~h}$. An attempt was made to achieve the complete conversion by increasing the reaction time to $24 \mathrm{~h}$, but the conversion of $\mathbf{6 c}$ could not been improved any further. These results may be caused by the deactivation of the catalyst or the competitiveness of dinitriles (6) and aminonitriles (7) for the same active sites. Whereas, recycling the studied catalyst was opposed by the deactivation. However, this process proved to be suitable for the selective formation of other aminonitriles from the corresponding aromatic dinitriles (Table 8). The lowest catalyst activity was observed in the hydrogenation of ortho-compound (Table 8, entry 3 ) which was attributed to a steric effect.

\subsection{Ir-catalyzed hydrogenations}

Iridium is not a typical catalytic metal for the hydrogenation of nitriles. However, when $0.9 \% \mathrm{Ir} / \gamma-\mathrm{Al}_{2} \mathrm{O}_{3}$ catalyst was applied in the reduction of benzonitrile in ethanol, at 21 bar and $100{ }^{\circ} \mathrm{C}, 50 \%$ conversion and $15 \%$ selectivity to benzylamine were achieved after $4 \mathrm{~h}$ [70].

\subsection{Reductions over platinum}

Platinum-catalyzed hydrogenation of nitriles almost exclusively resulted in secondary [3, 4, 71-73] or tertiary amines [74], but in some cases moderate primary amine selectivities (51-56\%) were achieved over supported platinum catalysts, in the gas-phase hydrogenation of acetonitrile $[75,76]$. Thus, $51 \%$ or $56 \%$ selectivity to ethylamine was obtained over a $1 \% \mathrm{Pt} /\left(\mathrm{Al}_{2} \mathrm{O}_{3}\right)_{0.25}(\mathrm{MgO})_{0.75}[75]$ or a $1 \%$ $\mathrm{Pt} / \mathrm{CeO}_{2}$ catalyst [76], at $20 \%$ conversion of acetonitrile, at atmospheric pressure and $70{ }^{\circ} \mathrm{C}$.

\section{Mechanistic considerations for the adsorption of nitriles on metals}

The reasons for the differences in hydrogenation selectivity can be related to the electronic properties of the $d$-bands of catalytic metals. Furthermore, it is generally accepted that the observed differences regarding the kinetic course of the hydrogenation (the shape of the conversion curve, catalyst deactivation rate) could be caused by the different adsorption strengths of the reaction components on several metals [3, 77-79].

The weak point in these conclusions, that the relative adsorption strengths are achieved indirectly from kinetic experiments. The different adsorption strengths may also be responsible for the differences in the selectivities of hydrogenations. However, it seems more probable, that the differences in the selectivities catalyzed by various metals could be caused by the diverse ways of the reactive intermediates bound onto the metal surface.

Over the past decade, several mechanistic proposals were published suggesting surface reaction steps and surface intermediates [16, 17, 80-86]. In 2010, an innovative and comprehensive model of heterogeneously catalyzed nitrile hydrogenation was introduced by Krupka [87], which is based on the already existing concepts of the mechanism [16, 17, 80-86], and applied the already existing knowledge of the kinetics of the reaction and the latest conclusions on the adsorption of $N$-containing substances on metals. The suggested concept helps to understand the differences in the hydrogenation selectivity of the individual metal catalysts. According to this proposal, under common reaction conditions $\left(<150{ }^{\circ} \mathrm{C}\right.$, elevated hydrogen pressure), nickel and cobalt prefer to form intermediates bound onto the surface of metal catalyst through the free electron pair on the nitrogen atom, while palladium and platinum prefer to form intermediates bound onto the surface through the $\alpha$-carbon atom or the $\pi$-system of a $\mathrm{C}=\mathrm{N}$ double bond (Fig. 8). Thus, the nitrile hydrogenation on cobalt or nickel surfaces will lead to the formation of nitrene intermediates (22). Due to the saturated $\alpha$-carbon atom, this species is inactive for condensation reactions, thereby, it favors the formation of primary amines. Whereas, during the hydrogenation on palladium or platinum surfaces, aldimines (23) or aminocarbene complexes (24) coordinate to the metal. In this case, due to the presence of the unsaturated electrophilic $\alpha$-carbon atom, both complexes are highly reactive, which leads to the formation of secondary and tertiary amines. 


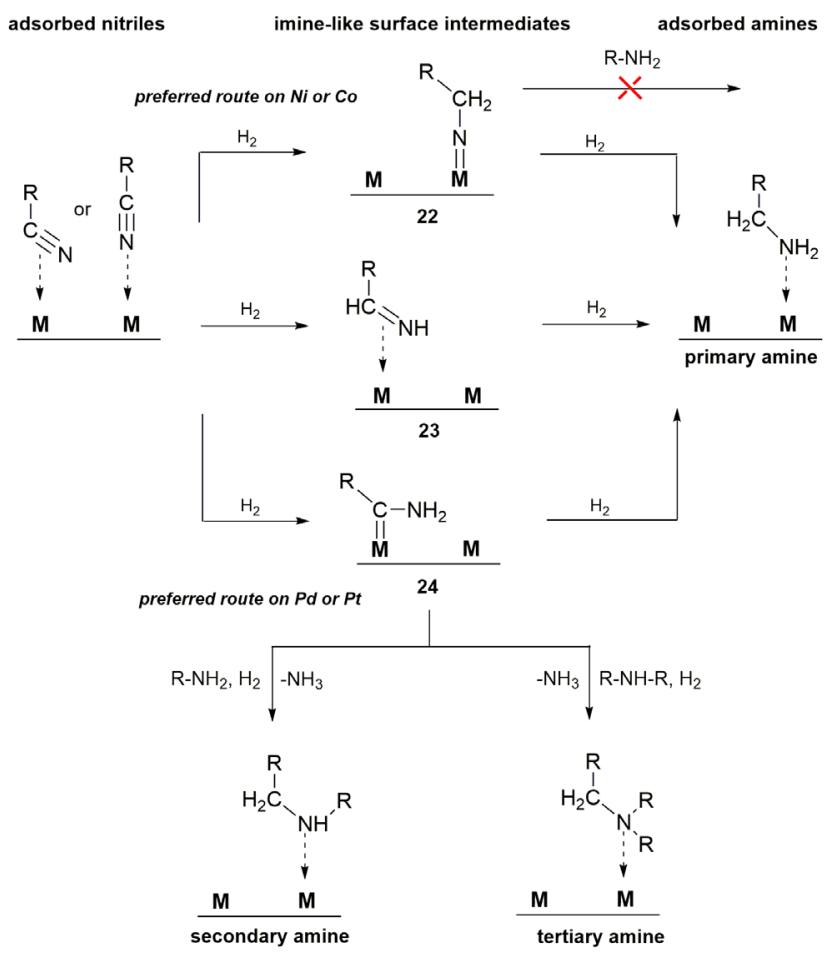

Fig. 8 Mechanistic proposal of surface reactions for heterogeneous nitrile hydrogenation suggested by Krupka [87]

"M" is the active site (one or more surface atoms) of the catalytic metal

\section{Influence of metallic particle size on selectivity and activity}

Some researchers suggested that the heterogeneous catalytic hydrogenation of nitriles is a structure sensitive reaction [71, 74, 88], while others found no correlation between the selectivity or activity, as well as the particle size of catalytic metal [76].

It was observed by Arai et al. that the gas-phase hydrogenation of acetonitrile over $\mathrm{Pt} / \mathrm{SiO}_{2}$ catalysts [74] or nickel on various oxide supports [88] was sensitive to the degree of metal dispersion. Whereas, the different particle sizes of these metals had effect on the initial specific activity only, namely it decreased by an increase in the degree of metal dispersion, while the product distribution was not dependent on the particle size of $\mathrm{Pt}$ or $\mathrm{Ni}$, because triethylamine (over platinum) or ethylamine (over nickel) was the main product. Thus, the selectivity have to depend on other attributes of the heterogeneous catalysts (e.g. supports).

\section{Effect of supports}

Various materials, like activated carbon [42, 46-53, 65, 73], alumina $[15,31-34,43,45,46,51,52,54-62,67,69-71,75$, 76, 88, 89], silica [7, 26-30, 41, 64, 66, 71, 72, 74, 76, 88, 89], titania [46, 71, 88], sepiolite [35], MCM-41 [63], hydrotalcite [81], ceria [76] or magnesia [44, 75, 76, 89], were used for as catalyst supports in the hydrogenation of nitriles.

These different supports, as usual, had significant influence on the catalyst activity, but their effects on the selectivity of catalytic metals were less often observed in this reaction [76, 81, 88, 89].

Verhaak et al. [89] found that the acidity of the support led a bifunctional mechanism which favored the condensation side-reaction in the vapor-phase hydrogenation of acetonitrile, over nickel on different supports $\left(\mathrm{Al}_{2} \mathrm{O}_{3}, \mathrm{SiO}_{2}, \mathrm{MgO}\right)$. As a result, catalysts with acidic supports exhibited a low selectivity to primary amines, while basic nickel ones were highly selective to the formation of ethylamine.

In 2017, Pirault-Roy et al. [76] investigated the influence of acid-base properties of the support on the catalytic performances of Pt-based catalysts in a gas-phase hydrogenation of acetonitrile, at atmospheric pressure and $70{ }^{\circ} \mathrm{C}$. Their results suggest that the activity and selectivity to primary amines or condensation reactions seem to be independent from Brønsted acidity of the supports $\left(\mathrm{Al}_{2} \mathrm{O}_{3}, \mathrm{MgO}, \mathrm{SiO}_{2}\right.$ or $\left.\mathrm{CeO}_{2}\right)$. Furthermore, a clear correlation was evidenced between the catalyst selectivity and the amount of basic sites: the higher the number of basic site was, the higher the formation of primary amines was. The best primary amine selectivity (56\%) was achieved by using a $1 \% \mathrm{Pt} / \mathrm{CeO}_{2}$ catalyst, at $20 \%$ conversion.

\section{Conclusion}

Although the heterogeneous catalytic hydrogenation of nitriles to primary amines is a highly atom-efficient process and results in important fine chemical intermediates, the formation of by-products, such as secondary / tertiary amines, decreases the selectivity of the reaction. However, some of the heterogeneous catalysts developed recently showed high activity and excellent selectivity to primary amines. Most results suggest that the selectivity is affected by the chemical nature of the metal, while the support increases the metal dispersion and thus, the catalyst activity. Besides, it is still not clearly explained whether the side-reactions proceed in the liquid phase or on the surface of the catalytic metal.

Further investigations to develop more efficient heterogeneous hydrognation processes for the selective synthesis of primary amines (new catalyst recycling methods, extension of the well-functioning procedures) are still expected. 


\section{References}

[1] Roose, P., Eller, K., Henkes, E., Rossbacher, R., Höke, H. "Amines, Aliphatic", In: Ullmann's Encyclopedia of Industrial Chemistry, 7th ed., Wiley-VCH Verlag GmbH \& Co. KGaA, Weinheim, Germany, 2015, pp. 1-55. https://doi.org/10.1002/14356007.a02_001.pub2

[2] Weissermel, K., Arpe, H.-J. "Industrial Organic Chemistry", 3rd rev. ed., VCH, Weinheim, Germany, 1997.

[3] Rylander, P. N. "Catalytic Hydrogenation over Platinum Metals", Academic Press, New York, USA, pp. 203-226, 1967.

[4] Freifelder, M. "Practical Catalytic Hydrogenation: Techniques and Applications", Wiley, New York,USA, pp. 238-260, 1971.

[5] Rylander, P. N. "Catalytic Hydrogenation in Organic Syntheses", Academic Press, New York, USA, pp. 138-140, 1979.

[6] von Braun, J., Blessing, G., Zobel, F. "Katalytische Hydrierungen unter Druck bei Gegenwart von Nickelsalzen, VI.: Nitrile", (Catalytic hydrogenations under pressure in the presence of nickel salts, VI.: Nitrile), Berichte der deutschen chemischen Gesellschaft (A and B Series), 56(8), pp. 1988-2001, 1923. (in German) https://doi.org/10.1002/cber.19230560845

[7] Greenfield, H. "Catalytic Hydrogenation of Butyronitrile", Journal of Industrial and Engineering Chemistry Product Research and Development, 6(2), pp. 142-144, 1967. https://doi.org/10.1021/i360022a014

[8] Bagal, D. B., Bhanage, B. M. "Recent Advances in Transition Metal-Catalyzed Hydrogenation of Nitriles", Advanced Synthesis \& Catalysis, 357(5), pp. 883-900, 2015. https://doi.org/10.1002/adsc.201400940

[9] Krupka, J., Pasek, J., "Nitrile Hydrogenation on Solid Catalysts - New Insights into the Reaction Mechanism", Current Organic Chemistry, 16(8), pp. 988-1004, 2012. https://doi.org/10.2174/138527212800194692

[10] Huber, W. "Hydrogenation of Basic Nitriles with Raney Nickel", Journal of the American Chemical Society, 66(6), pp. 876-879, 1944. https://doi.org/10.1021/ja01234a009

[11] Degischer, O. G., Roessler, F., Rys, P. "Catalytic Hydrogenation of Benzonitrile over Raney Nickel", In: Ford, M. E. (ed.) Catalysis of Organic Reactions, Chemical Industries Series, 82, Marcel Dekker, New York, USA, 2001, pp. 241-254.

[12] Gomez, S., Peters, J. A., Maschmeyer, T. "The Reductive Amination of Aldehydes and Ketones and the Hydrogenation of Nitriles: Mechanistic Aspects and Selectivity Control", Advanced Synthesis \& Catalysis, 344(10), pp. 1037-1057, 2002.

https://doi.org/10.1002/1615-4169(200212)344:10<1037::AID-AD$\mathrm{SC} 1037>3.0 . \mathrm{CO} ; 2-3$

[13] Bawane, S. P., Sawant, S. B. "Reaction kinetics of the liquid-phase hydrogenation of benzonitrile to benzylamine using Raney nickel catalyst", Chemical Engineering Journal, 103(1-3), pp. 13-29, 2004. https://doi.org/10.1016/j.cej.2004.07.002

[14] Kukula, P., Studer, M., Blaser, H.-U. "Chemoselective Hydrogenation of $\alpha, \beta$-Unsaturated Nitriles", Advanced Synthesis \& Catalysis, 346(12), pp. 1487-1493, 2004. https://doi.org/10.1002/adsc.200404128
[15] Freifelder, M. "A Low Pressure Process for the Reduction of Nitriles. Use of Rhodium Catalyst", Journal of the American Chemical Society, 82(9), pp. 2386-2389, 1960.

https://doi.org/10.1021/ja01494a067

[16] de Bellefon, C., Fouilloux, P. "Homogeneous and Heterogeneous Hydrogenation of Nitriles in a Liquid Phase: Chemical, Mechanistic, and Catalytic Aspects", Catalysis Reviews: Science and Engineering, 36(3), pp. 459-506, 1994. https://doi.org/10.1080/01614949408009469

[17] Chojecki, A., Veprek-Heijman, M., Müller, T. E., Schärringer, P., Veprek, S., Lercher, J. A. "Tailoring Raney-catalysts for the selective hydrogenation of butyronitrile to $n$-butylamine", Journal of Catalysis, 245(1), pp. 237-248, 2007. https://doi.org/10.1016/j.jcat.2006.10.012

[18] Johnson, T. A., Freyberger, D. P. "Lithium Hydroxide Modified Sponge Catalysts for Control of Primary Amine Selectivity in Nitrile Hydrogenation", In: Ford, M. E. (ed.) Catalysis of Organic Reactions, Chemical Industries Series, 82, Marcel Dekker, New York, USA, 2001, pp. 201-227.

[19] Hartung, W. H., "Catalytic Reduction of Nitriles and Oximes", Journal of the American Chemical Society, 50(12), pp. 3370$3374,1928$. https://doi.org/10.1021/ja01399a033

[20] Miller, E., Sprague, J. M., Kissinger, L. W., McBurney, L. F. "The Preparation of Some Amino Sulfonamides", Journal of the American Chemical Society, 62(8), pp. 2099-2103, 1940. https://doi.org/10.1021/ja01865a053

[21] Schwartz, M. A., Zoda, M., Vishnuvajjala, B., Mami, I., "A convenient synthesis of $\mathrm{o}$ - and $\mathrm{p}$-hydroxy substituted phenylacetonitriles and phenethylamines", The Journal of Organic Chemistry, 41(14), pp. 2502-2503, 1976 https://doi.org/10.1021/jo00876a038

[22] Carothers, W. H., Jones, G. A., "The preparation of some primary amines by the catalytic reduction of nitriles", Journal of the American Chemical Society, 47(12), pp. 3051-3057, 1925. https://doi.org/10.1021/ja01689a034

[23] Overberger, C. G., Mulvaney, J. E. "Synthesis and Polymerization of Methyl Substituted Vinylcyclohexanes", Journal of the American Chemical Society, 81(17), pp. 4697-4701, 1959. https://doi.org/10.1021/ja01526a063

[24] Gould, F., Johnson, G., Ferris, A. "Notes- The Hydrogenation of Nitriles to Primary Amines", The Journal of Organic Chemistry, 25(9), pp. 1658-1660, 1960. https://doi.org/10.1021/jo01079a600

[25] Hoffer, B. W., Moulijn, J. A. "Hydrogenation of dinitriles on Raney-type Ni catalysts: kinetic and mechanistic aspects", Applied Catalysis A: General, 352(1-2), pp. 193-201, 2009. https://doi.org/10.1016/j.apcata.2008.10.004

[26] Zhang, P., Zhang, Q., Li, X. "Preparation of m-xylylenediamine by hydrogenation of isophtalonitrile on $\mathrm{Ni}-\mathrm{Ru} / \mathrm{SiO}_{2}$ catalysts", Industrial Catalysis, 7, pp. 71-75, 2012. https://doi.org/10.3969/j.issn.1008-1143.2012.07.017 
[27] Segobia, D. J., Trasarti, C. R., Apesteguía, C. R. "Hydrogenation of nitriles to primary amines on metal-supported catalysts: Highly selective conversion of butyronitrile to n-butylamine", Applied Catalysis A: General, 445-446, pp. 69-75, 2012. https://doi.org/10.1016/j.apcata.2012.08.006

[28] Segobia, D. J., Trasarti, C. R., Apesteguía, C. R. "Synthesis of $n$-Butylamine from Butyronitrile on $\mathrm{Ni} / \mathrm{SiO}_{2}$ : Effect of Solvent", Journal of the Brazilian Chemical Society, 25(12), pp. 2272-2279, 2014. https://doi.org/10.5935/0103-5053.20140215

[29] Jia, Z., Zhen, B., Han, M., Wang, C. "Liquid phase hydrogenation of adiponitrile over directly reduced $\mathrm{Ni} / \mathrm{SiO}_{2}$ catalyst", Catalysis Communications, 73, pp. 80-83, 2016. http://doi.org/10.1016/j.catcom.2015.10.021

[30] Segobia, D. J., Trasarti, A. F., Apesteguía, C. R. "Chemoselective hydrogenation of unsaturated nitriles to unsaturated primary amines: Conversion of cinnamonitrile on metal-supported catalysts", Applied Catalysis A: General, 494, pp. 41-47, 2015. https://doi.org/10.1016/j.apcata.2015.01.028

[31] Liu, C., Wang, T. "Isophthalonitrile (IPN) hydrogenation over $\mathrm{K}$ modified $\mathrm{Ni}-\mathrm{Co}$ supported catalysts: catalyst characterization and performance evaluation", RSC Advances, 4(109), pp. 63725-63733, 2014 https://doi.org/10.1039/C4RA09607J

[32] Liu, C., Hou, R., Wang, T. "Role of acid sites and surface hydroxyl groups in isophthalonitrile hydrogenation catalyzed by supported Ni-Co catalysts", RSC Advances, 5(34), pp. 26465-26474, 2015. https://doi.org/10.1039/C5RA01007A

[33] Liu, C., Li, X., Wang, T. "Catalytic hydrogenation of isophthalonitrile (IPN) over supported monometallic and bimetallic catalysts", RSC Advances, 5(71), pp. 57277-57285, 2015. https://doi.org/10.1039/C5RA10231F

[34] Cheng, H., Meng, X., Wu, C., Shan, X., Yu, Y., Zhao, F. "Selective hydrogenation of benzonitrile in multiphase reaction systems including compressed carbon dioxide over $\mathrm{Ni} / \mathrm{Al}_{2} \mathrm{O}_{3}$ catalyst", Journal of Molecular Catalysis A: Chemical, 379, pp. 72-79, 2013. https://doi.org/10.1016/j.molcata.2013.07.017

[35] Lv, Y., Hao, F., Liu, P., Xiong, S., Luo, H. "Liquid phase hydrogenation of adiponitrile over acid-activated sepiolite supported $\mathrm{K}-$ La-Ni trimetallic catalysts", Reaction Kinetics, Mechanisms and Catalysis, 119(2), pp. 555-568, 2016. https://doi.org/10.1007/s11144-016-1061-2

[36] Zhang, P., Du, W., Rong, Z., Wang, Y., Lü, L. "Mild Hydrogenation of Benzonitrile to Benzylamine over Amorphous NiAl Alloy Catalyst", Petrochemical Technology, 10, pp. 1037-1041, 2007. https://doi.org/10.3321/j.issn:1000-8144.2007.10.013

[37] Cao, Y., Niu, L., Wen, X., Feng, W., Huo, L., Bai, G. "Novel layered double hydroxide / oxide-coated nickel-based core-shell nanocomposites for benzonitrile selective hydrogenation: An interesting water switch", Journal of Catalysis, 339, pp. 9-13, 2016. https://doi.org/10.1016/j.jcat.2016.03.015

[38] Mokhov, V. M., Popov, Y. V., Shcherbakova, K. V. "Colloid and nanosized catalysts in organic synthesis: XII. Hydrogenation of carbonitriles catalyzed by nickel nanoparticles", Russian Journal of General Chemistry, 86(2), pp. 273-280, 2016. https://doi.org/10.1134/S1070363216020110
[39] Konnerth, H., Precht1, M. H. G. "Nitrile hydrogenation using nickel nanocatalysts in ionic liquids", New Journal of Chemistry, 41(18), pp. 9594-9597, 2017. https://doi.org/10.1039/C7NJ02210G

[40] Zen, Y.-F., Fu, Z.-C., Liang, F., Xu, Y., Yang, D.-D., Yang, Z., Gan, X., Lin, Z.-S., Chen, Y., Fu, W.-F. "Robust Hydrogenation of Nitrile and Nitro Groups to Primary Amines Using $\mathrm{Ni}_{2} \mathrm{P}$ as a Catalyst and Ammonia Borane under Ambient Conditions", Asian Journal of Organic Chemistry, 6(11), pp. 1589-1593, 2017. https://doi.org/10.1002/ajoc.201700383

[41] Ansmann, A., Benisch, C. "Supported cobalt catalysts for nitrile hydrogenations", United States Patent, Assignee: BASF Aktiengesellschaft, Ludwigshafen, Germany, US 6790996 B2, 2004.

[42] Long, J., Shen, K., Li, Y. "Bifunctional N-Doped Co@C Catalysts for Base-Free Transfer Hydrogenations of Nitriles: Controllable Selectivity to Primary Amines vs Imines", ACS Catalysis, 7(1), pp. 275-284, 2017.

https://doi.org/10.1021/acscatal.6b02327

[43] Chen, F., Topf, C., Radnik, J., Kreyenschulte, C., Lund, H., Schneider, M., Surkus, A.-E., He, L., Junge, K., Beller, M. "Stable and Inert Cobalt Catalysts for Highly Selective and Practical Hydrogenation of $\mathrm{C} \equiv \mathrm{N}$ and $\mathrm{C}=\mathrm{O}$ Bonds", Journal of the American Chemical Society, 138(28), pp. 8781-8788, 2016. https://doi.org/10.1021/jacs.6b03439

[44] Marella, R. K., Koppadi, K. S., Jyothi, Y., Rama Rao, K. S., Burri, D. R. "Selective gas-phase hydrogenation of benzonitrile into benzylamine over $\mathrm{Cu}-\mathrm{MgO}$ catalysts without using any additives", New Journal of Chemistry, 37(10), pp. 3229-3235, 2013. https://doi.org/10.1039/C3NJ00453H

[45] Lin, C., Li, J., Guo, H., Wu, X., Wang, B., Yan, X. "Controllable synthesis of bis[3-(dimethylamino)propyl]amine over $\mathrm{Cr}$ and Co double-doped $\mathrm{Cu} / \gamma-\mathrm{Al}_{2} \mathrm{O}_{3}$ ", Catalysis Communications, 111, pp. 64-69, 2018 https://doi.org/10.1016/j.catcom.2018.03.031

[46] Hegedűs, L., Máthé, T. "Selective heterogeneous catalytic hydrogenation of nitriles to primary amines in liquid phase: Part I. Hydrogenation of benzonitrile over palladium", Applied Catalysis A: General, 296(2), pp. 209-215, 2005. https://doi.org/10.1016/j.apcata.2005.08.024

[47] Hegedűs, L., Máthé, T., Kárpáti, T. "Selective heterogeneous catalytic hydrogenation of nitriles to primary amines in liquid phase: Part II: Hydrogenation of benzyl cyanide over palladium", Applied Catalysis A: General, 349(1-2), pp. 40-45, 2008. https://doi.org/10.1016/j.apcata.2008.07.012

[48] Yap, A. J., Chan, B., Yuen, A. K. L., Ward, A. J., Masters, A. F., Maschmeyer, T. "A Palladium-Catalyzed Multicascade Reaction: Facile Low-Temperature Hydrogenolysis of Activated Nitriles and Related Functional Groups", ChemCatChem, 3(9), pp. 1496-1502, 2011. https://doi.org/10.1002/cctc.201100076

[49] Vilches-Herrera, M., Werkmeister, S., Junge, K., Börner, A., Beller, M. "Selective catalytic transfer hydrogenation of nitriles to primary amines using Pd/C", Catalysis Science \& Technology, 4(3), pp. 629-632, 2014. http://doi.org/10.1039/C3CY00854A 
[50] Hao, Y., Wang, X., Perret, N., Cárdenas-Lizana, F., Keane, M. A. "Support effects in the gas phase hydrogenation of butyronitrile over palladium", Catalysis, Structure \& Reactivity, 1(1), pp. 4-10, 2015. https://doi.org/10.1179/2055075814Y.0000000002

[51] Hao, Y., Li, M., Cárdenas-Lizana, F., Keane, M. A. "Selective Production of Benzylamine via Gas Phase Hydrogenation of Benzonitrile over Supported Pd Catalysts", Catalysis Letters, 146(1), pp. 109-116, 2016. https://doi.org/10.1007/s10562-015-1655-8

[52] McMillan, L., Gilpin, L. F., Baker, J., Brennan, C., Hall, A., Lundie, D. T., Lennon, D. "The application of a supported palladium catalyst(s) for the hydrogenation of aromatic nitriles", Journal of Molecular Catalysis A: Chemical, 411, pp. 239-246, 2016. https://doi.org/10.1016/j.molcata.2015.10.028

[53] McAllister, M. I., Boulho, C., McMillan, L., Gilpin, L. F., Wiedbrauk, S., Brennan, C., Lennon, D. "The production of tyramine via the selective hydrogenation of 4-hydroxybenzyl cyanide over a carbon-supported palladium catalyst", RSC Advances, 8(51), pp. 29392-29399, 2018. https://oi.org/10.1039/C8RA05654D

[54] Bakker, J. J. W., van der Neut, A. G., Kreutzer, M. T., Moulijn, J. A., Kapteijn, F. "Catalyst performance changes induced by palladium phase transformation in the hydrogenation of benzonitrile", Journal of Catalysis, 274(2), pp. 176-191, 2010.

https://doi.org/10.1016/j.jcat.2010.06.013

[55] Yoshida, H., Wang, Y., Narisawa, S., Fujita, S., Liu, R., Arai, M. "A multiphase reaction medium including pressurized carbon dioxide and water for selective hydrogenation of benzonitrile with a $\mathrm{Pd} / \mathrm{Al}_{2} \mathrm{O}_{3}$ catalyst", Applied Catalysis A: General, 456, pp. 215-222, 2013.

https://doi.org/10.1016/j.apcata.2013.03.004

[56] Bhosale, A., Yoshida, H., Fujita, S., Arai, M. "Selective hydrogenation of benzyl cyanide to 2-phenylethylamine over a $\mathrm{Pd} / \mathrm{Al}_{2} \mathrm{O}_{3}$ catalyst promoted by synergistic effects of $\mathrm{CO}_{2}$ and water", Green Chemistry, 17(2), pp. 1299-1307, 2015.

http://doi.org/10.1039/C4GC02118E

[57] Bhosale, A., Yoshida, H., Fujita, S., Arai, M. "Carbon dioxide and water: An effective multiphase medium for selective hydrogenation of nitriles with a $\mathrm{Pd} / \mathrm{Al}_{2} \mathrm{O}_{3}$ catalyst", Journal of $\mathrm{CO} 2$ Utilization, 16, pp. 371-374, 2016. https://doi.org/10.1016/j.jcou.2016.09.006

[58] Dai, C., Liu, F., Zhang, W., Li, Y., Ning, C., Wang, X., Zhang, C. "Deactivation study of $\mathrm{Pd} / \mathrm{Al}_{2} \mathrm{O}_{3}$ catalyst for hydrogenation of benzonitrile in fixed-bed reactor", Applied Catalysis A: General, 538, pp. 199-206, 2017.

https://doi.org/10.1016/j.apcata.2017.03.030

[59] Dai, C., Zhu, S., Wang, X., Zhang, C., Zhang, W., Li, Y., Ning, C. "Efficient and selective hydrogenation of benzonitrile to benzylamine: improvement on catalytic performance and stability in a trickle-bed reactor", New Journal of Chemistry, 41(10), pp. 3758-3765, 2017. https://doi.org/10.1039/C7NJ00001D

[60] Dai, C., Li, Y., Ning, C., Zhang, W., Wang, X., Zhang, C. "The influence of alumina phases on the performance of $\mathrm{Pd} / \mathrm{Al}_{2} \mathrm{O}_{3}$ catalyst in selective hydrogenation of benzonitrile to benzylamine", Applied Catalysis A: General, 545, pp. 97-103, 2017. https://doi.org/10.1016/j.apcata.2017.07.032
[61] Yoshimura, M., Komatsu, A., Niimura, M., Takagi, Y., Takahashi, T., Ueda, S., Ichikawa, T., Kobayashi, Y., Okami, H., Hattori, T., Sawama, Y., Monguchi, Y., Sajiki, H. "Selective Synthesis of Primary Amines from Nitriles under Hydrogenation Conditions", Advanced Synthesis \& Catalysis, 360(8), pp. 1726-1732, 2018. https://doi.org/10.1002/adsc.201800102

[62] Lin, C., Wang, B., Guo, H., Chen, L., Yan, X. "Selective Synthesis of $N, N$-Bis(3-dimethylaminopropyl)amine over $\mathrm{Pd} / \gamma-\mathrm{Al}_{2} \mathrm{O}_{3}$ ", Bulletin of the Korean Chemical Society, 39(3), pp. 391-396, 2018. https://doi.org/10.1002/bkcs.11401

[63] Chatterjee, M., Kawanami, H., Sato, M., Ishizaka, T., Yokoyama, T., Suzuki, T. "Hydrogenation of nitrile in supercritical carbon dioxide: a tunable approach to amine selectivity", Green Chemistry, 12(1), pp. 87-93, 2010. https://doi.org/10.1039/B913828E

[64] Hao, Y., Li, M., Cárdenas-Lizana, F., Keane, M. A. "Production of Butylamine in the Gas Phase Hydrogenation of Butyronitrile over $\mathrm{Pd} / \mathrm{SiO}_{2}$ and $\mathrm{Ba}-\mathrm{Pd} / \mathrm{SiO}_{2}$ ", Catalysis, Structure \& Reactivity, 1(3), pp. 132-139, 2015.

https://doi.org/10.1179/2055075815Y.0000000007

[65] Obert, K., Roth, D., Ehrig, M., Schönweiz, A., Assenbaum, D., Lange, H., Wasserscheid, P. "Selectivity enhancement in the catalytic hydrogenation of propionitrile using ionic liquid multiphase reaction systems", Applied Catalysis A: General, 356(1), pp. 43-51, 2009.

https://doi.org/10.1016/j.apcata.2008.12.016

[66] Segobia, D. J., Trasarti, A. F., Apesteguía, C. R. "Conversion of butyronitrile to butylamines on noble metals: effect of the solvent on catalyst activity and selectivity", Catalysis Science \& Technology, 4(11), pp. 4075-4083, 2014.

https://doi.org/10.1039/C4CY00741G

[67] Muratsugu, S., Kityakarn, S., Wang, F., Ishiguro, N., Kamachi, T., Yoshizawa, K., Sekizawa, O., Uruga, T., Tada, M. "Formation and nitrile hydrogenation performance of Ru nanoparticles on a K-doped $\mathrm{Al}_{2} \mathrm{O}_{3}$ surface", Physical Chemistry Chemical Physics, 17(38), pp. 24791-24802, 2015.

https://doi.org/10.1039/C5CP03456F

[68] Ortiz-Cervantes, C., Iyañez, I., García, J. J. "Facile preparation of ruthenium nanoparticles with activity in hydrogenation of aliphatic and aromatic nitriles to amines", Journal of Physical Organic Chemistry, 25(11), pp. 902-907, 2012.

https://doi.org/10.1002/poc.2962

[69] Chatterjee, M., Sato, M., Kawanami, H., Yokoyama, T., Suzuki, T., Ishizaka, T. "An Efficient Hydrogenation of Dinitrile to Aminonitrile in Supercritical Carbon Dioxide", Advanced Synthesis \& Catalysis, 352(14-15), pp. 2394-2398, 2010. https://doi.org/10.1002/adsc.201000514

[70] López-De Jesús, Y. M., Johnson, C. E., Monnier, J. R., Williams, C. T. "Selective Hydrogenation of Benzonitrile by AluminaSupported Ir-Pd Catalysts", Topics in Catalysis, 53(15-18), pp. 1132-1137, 2010. https://doi.org/10.1007/s11244-010-9546-0

[71] Arai, M., Takada, Y., Ebina, T., Shirai, M. "Effects of supports in gas-phase hydrogenation of acetonitrile over supported platinum catalysts", Applied Catalysis A: General, 183(2), pp. 365-376, 1999. https://doi.org/10.1016/S0926-860X(99)00072-1 
[72] Göbölös, S., Mahata, N., Borbáth, I., Hegedűs, M., Margitfalvi, J. L. "Hydrogenation of Benzonitrile on $\mathrm{Sn}-\mathrm{Pt} / \mathrm{SiO}_{2}$ Catalysts Prepared by Introducing $\mathrm{SnEt}_{4}$ to $\mathrm{Pt} / \mathrm{SiO}_{2}$ : Role of Tin", Reaction Kinetics and Catalysis Letters, 74(2), pp. 345-352, 2001. https://doi.org/10.1023/A:1017957715767

[73] Sharma, S. K., Lynch, J., Sobolewska, A. M., Plucinski, P., Watson, R. J., Williams J. M. J. "Pt/C catalysed direct reductive amination of nitriles with primary amines in a continuous flow multichannel microreactor", Catalysis Science \& Technology, 3(1), pp. 85-88, 2013. https://doi.org/10.1039/C2CY20431B

[74] Arai, M., Takada, Y., Nishiyama, Y. "Effects of Metal Particle Size in Gas-Phase Hydrogenation of Acetonitrile over Silica-Supported Platinum Catalysts", The Journal of Physical Chemistry B, 102(11), pp. 1968-1973, 1998. https://doi.org/10.1021/jp9726293

[75] Poupin, C., Maache, R., Pirault-Roy, L., Brahmi, R., Williams, C. T. "Effect of $\mathrm{Al}_{2} \mathrm{O}_{3} / \mathrm{MgO}$ molar ratio on catalytic performance of $\mathrm{Pt} / \mathrm{MgO}-\mathrm{Al}_{2} \mathrm{O}_{3}$ catalyst in acetonitrile hydrogenation followed by Fourier transform infrared spectroscopy", Applied Catalysis A: General, 475, pp. 363-370, 2014. https://doi.org/10.1016/j.apcata.2014.01.041

[76] Saad, F., Comparot, J. D., Brahmi, R., Bensitel, M., Pirault-Roy, L. "Influence of acid-base properties of the support on the catalytic performances of Pt-based catalysts in a gas-phase hydrogenation of acetonitrile", Applied Catalysis A: General, 544, pp. 1-9, 2017. https://doi.org/10.1016/j.apcata.2017.06.038

[77] Volf, J., Pašek, J. "Chapter 4 Hydrogenation of Nitriles", In: Cerveny, L. (ed.) Catalytic Hydrogenation, Studies in Surface Science and Catalysis Series, Vol. 27, 1st ed., Elsevier Science, 1986, pp. 105-144. https://doi.org/10.1016/S0167-2991(08)65350-1

[78] Huang, Y., Sachtler, W. M. H. "On the mechanism of catalytic hydrogenation of nitriles to amines over supported metal catalysts", Applied Catalysis A: General, 182(2), pp. 365-378, 1999. https://doi.org/10.1016/S0926-860X(99)00035-6

[79] Krupka, J., Pašek, J., Navrátilová, M. "Hydrogenation of 3-(Dimethylamino)propionitrile Over Palladium Catalysts", Collection of Czechoslovak Chemical Communications, 65, pp. $1805-1819,2000$ https://doi.org/10.1135/cccc20001805

[80] Chojecki, A., Jobic, H., Jentys, A., Müller, T. E., Lercher, J. A. "Inelastic Neutron Scattering of Hydrogen and Butyronitrile Adsorbed on Raney-Co Catalysts", Catalysis Letters, 97(3-4), pp. 155-162, 2004. https://doi.org/10.1023/B:CATL.0000038578.67273.b0
[81] Coq, B., Tichit, D., Ribet, S. "Co/Ni/Mg/Al Layered Double Hydroxides as Precursors of Catalysts for the Hydrogenation of Nitriles: Hydrogenation of Acetonitrile", Journal of Catalysis, 189(1), pp. 117-128, 2000

https://doi.org/10.1006/jcat.1999.2694

[82] Schärringer, P., Müller, T. E., Lercher, J. A. "Investigations into the mechanism of the liquid-phase hydrogenation of nitriles over Raney-Co catalysts", Journal of Catalysis, 253(1), pp. 167-179, 2008. https://doi.org/10.1016/j.jcat.2007.10.008

[83] Schärringer, P., Müller, T. E., Jentys, A., Lercher, J. A. "Identification of reaction intermediates during hydrogenation of $\mathrm{CD}_{3} \mathrm{CN}$ on Raney-Co", Journal of Catalysis, 263(1), pp. 34-41, 2009. https://doi.org/10.1016/j.jcat.2009.01.009

[84] Huang, Y.-Y., Sachtler, W. M. H. "Catalytic hydrogenation of nitriles to prim., sec. and tert. amines over supported mono- and bimetallic catalysts", In: Corma, A., Melo, F. V., Mendioroz, S., Fierro, J. L. G. (eds.) 12th International Congress on Catalysis, Studies in Surface Science and Catalysis Series, Vol. 130, 1st ed., Elsevier Science, 2000, pp. 527-532. https://doi.org/10.1016/S0167-2991(00)81011-3

[85] Huang, Y., Sachtler, W. M. H. "Intermolecular Hydrogen Transfer in Nitrile Hydrogenation over Transition Metal Catalysts", Journal of Catalysis, 190(1), pp. 69-74, 2000. https://doi.org/10.1006/jcat.1999.2729

[86] Huang, Y., Sachtler, W. M. H. "Concerted Reaction Mechanism in Deuteration and H/D Exchange of Nitriles over Transition Metals", Journal of Catalysis, 184(1), pp. 247-261, 1999 https://doi.org/10.1006/jcat.1999.2445

[87] Krupka, J. "Mechanismus Heterogenně Katalyzované Hydrogenace Nitrilü", (Mechanism of The Heterogeneously Catalyzed Hydrogenation of Nitriles) Chemické Listy, 104(7), pp. 709-723, 2010. (in Czech) Available at: http://www.chemickelisty.cz/ojs3/index.php/chemicke-listy/article/view/1291 [Accessed: 1st July 2018]

[88] Rode, C. V., Arai, M., Shirai, M., Nishiyama Y. "Gas-phase hydrogenation of nitriles by nickel on various supports", Applied Catalysis A: General, 148(2), pp. 405-413, 1997. https://doi.org/10.1016/S0926-860X(96)00238-4

[89] Verhaak, M. J. F. M., van Dillen, A. J., Geus, J. W. "The selective hydrogenation of acetonitrile on supported nickel catalysts", Catalysis Letters, 26(1-2), pp. 37-53, 1994. https://doi.org/10.1007/BF00824030 